\title{
A GIANT PHYLLODES TUMOR
}

Pradip Sarkar ${ }^{1}$, Sumit Gupta², Dhurba Banik ${ }^{3}$

\section{HOW TO CITE THIS ARTICLE:}

Pradip Sarkar, Sumit Gupta, Dhurba Banik. "A Giant Phyllodes Tumor". Journal of Evolution of Medical and Dental Sciences 2014; Vol. 3, Issue 18, May 05; Page: 4874-4875, D0I: 10.14260/jemds/2014/2526

ABSTRACT: This is a case reporting the largest phyllodes tumor of breast in north east India. A 32 years old female presented with a large lump in right breast since last 1 year. This was the recurrence of lump in last 2 years. Biopsy from the lump proved to be cystosarcoma phyllodes. Simple Mastectomy was done as a curative procedure. The tumor measured exactly to be $35 \times 22.5 \times 24.5 \mathrm{~cm}$ in size and $5 \mathrm{~kg}$ in weight. Histopathological diagnosis of the tumor was borderline phyllodes tumor. Patient had an uneventful postoperative course and is presently on monthly follow up.

KEYWORDS: Phyllodes, Giant, Sarcoma.

INTRODUCTION: The phyllodes tumor was originally described by Johannes Muller in 1838. Classically, the name cystosarcoma Phyllodes was assigned because of the tumor's fleshy appearance and tendency to contain macroscopic cysts. The term, however, is a misnomer as these tumors are usually benign. Phyllodes tumor is the currently accepted nomenclature according to the World Health Organization (WHO). ${ }^{1}$

Phyllodes tumors are biphasic fibroepithelial neoplasms of breast ${ }^{1}$ which are generally classified as benign, borderline and malignant. ${ }^{2}$ Borderline tumors have great potential for local recurrence. They make up 0.3 to $0.5 \%$ of female breast tumors. ${ }^{3}$

Phyllodes tumors are sharply demarcated from surrounding tissue which is compressed and distorted. Connective tissue makes the bulk of tumors which have mixed solid and cystic areas. Most malignant phyllodes tumors are liposarcomas/rhabdomyosarcomas. Evaluation of number of mitosis helps in diagnosis of malignant tumor. ${ }^{2}$ Mitotic number of more than 10/HPF is usually considered as malignant. The arbitrary cut off point for designation as a giant phyllodes tumor is $10 \mathrm{~cm} .^{4}$

Usually wide local excision of the tumor with $1 \mathrm{~cm}^{1}$ breast margin may suffice as the treatment but larger malignant variety may require simple mastectomy as treatment pertaining to that individual case and number of recurrences. Radiotherapy may have a role in the treatment of phyllodes tumor depending of the number of recurrences, mitotic index, bulky tumor, status of the resection margins p53 and Ki67 expression. ${ }^{5}$

CASE REPORT: A 32-year-old female patient was admitted to our center with a large right breast mass for about 1year. This was the second recurrence in last 2 years.

On clinical examination right breast was hugely enlarged to $35 \times 22 \times 25 \mathrm{~cm}$ with altered contour and enlarged nipple areola complex. Skin was shining, smooth with bosselated surface. Biopsy from the lump proved to be cystosarcoma phyllodes.

As it was the recurrence simple Mastectomy with primary closure was planned for the patient as curative procedure. Intra operatively Pectoralis Major, Pectoralis Minor, Serratus Anterior were free from the tumor, also the axillary lymph nodes were not enlarged. Hence simple Mastectomy was done.

RESULT: The tumor specimen measured exactly to be $35 \times 21.5 \times 24.5$ in size and weight of $5 \mathrm{~kg}$. Microscopically the lesion was borderline phyllodes tumor with 1-2 mitotic activity per ten high 
power fields. Areas of hemorrhage and myxoid degeneration were present without any lymphovascular invasion.

Patient had an uneventful post-operative course and is presently on monthly follow up.

CONCLUSION: To our knowledge, this patient presented one of the biggest phyllodes tumors of breast in all cases reported in north east India.

\section{REFERENCES:}

1. Liang MI, Ramaswamy B, Patterson CC, McKelvey MT, Cordillo G, Nuovo GJ, Carson WE., III Giant breast tumors: surgical management of phyllodes tumors, potential for reconstructive surgery and review of literature. World Jr of Surgical Oncology. 2008; 6:117. doi: 10.1186/1477-78196-117.

2. Khan SA, Badve S. Phyllodes tumors of breast: Curr Treat options Oncol.2001; 2:139-147. doi: 10.1007/s11864-001-0056-y.

3. Rowell MD, Perry RR, Jeng-Gwang H, Barranco SC. Phyllodes tumors. Am J Surg.1993; 165:37679. doi: 10.1016/S0002-9610(05)80849-9.

4. Tan P-H, Jayabaskar T, Chuah K-L, Lee H-Y, Tan Y, Hilmy M, et al. Phyllodes tumors of the breast the role of pathologic parameters. Am J ClinPathol.2005; 123:529-540. doi: 10.1309/U6DVBFM81MLJC1FN.

5. Erhan Y, Zekioglu O, Ersoy O, Tugan D, Aydede H, Sakarya A, Kapkaç M, Ozdemir N, Ozbal O, Erhan Y. p53 and Ki-67 expression as prognostic factors in cystosarcoma phyllodes. Breast J.2002; 8(1):38-44. doi: 10.1046/j.1524-4741.2002.08008.x.

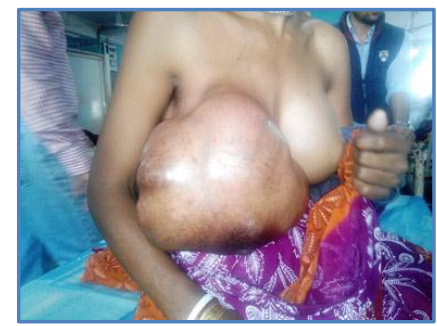

Fig. 1: (view in sitting position)

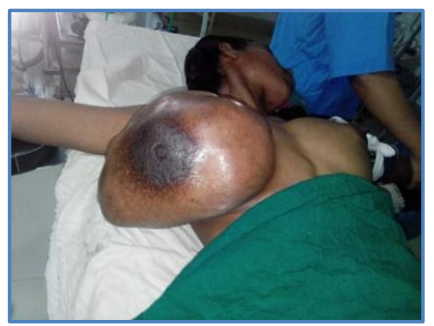

Fig. 1: (view in supine position)

\section{AUTHORS:}

1. Pradip Sarkar

2. Sumit Gupta

3. Dhurba Banik

\section{PARTICULARS OF CONTRIBUTORS:}

1. Associate Professor, Department of Surgery, Agartala Government Medical College, Agartala.

2. Post Graduate Student, Department of Surgery, Agartala Government Medical College, Agartala.

3. Registrar, Department of Surgery, Agartala Government Medical College, Agartala.

\section{NAME ADDRESS EMAIL ID OF THE CORRESPONDING AUTHOR:}

Dr. Sumit Gupta,

Room No. 15, Resident Quarters,

AGMC \& GBPH, Agartala.

E-mail: sumitgupta3210@gmail.com

Date of Submission: 31/03/2014.

Date of Peer Review: 01/04/2014.

Date of Acceptance: 09/04/2014.

Date of Publishing: 01/05/2014. 